Research Paper

\title{
The Radiosensitization of Sodium Glycididazole on Nasopharyngeal Carcinoma Cells via Enhancing DNA Damage and Promoting Apoptosis
}

\author{
Xiaoli Min1,2, Fangling Huang1, Huichao Huang1, Shuang Zhao1, Guoqiang Wang1, Minze Zhou1, Zhuchu \\ Chen ${ }^{1}$, Maoyu Li ${ }^{\bowtie}$, Yongheng Chen ${ }^{1 凶}$ \\ 1. Key Laboratory of Oncoproteomics of Chinese National Health and Family Planning Commission, Xiangya Hospital, Central South University, Changsha, \\ 410008, Hunan Province, China \\ 2. Department of Dermatology, Second Xiangya Hospital, Central South University, Hunan Key Laboratory of Medical Epigenomics, Changsha, 410008, \\ Hunan Province, China \\ $\triangle$ Corresponding authors: Yongheng Chen, PhD, Professor, Key Laboratory of Oncoproteomics of Chinese National Health and Family Planning, Xiangya \\ Hospital, Central South University, Changsha, Hunan, P.R. China. Email: yonghenc@163.com; Maoyu Li, MD, Key Laboratory of Oncoproteomics of Chinese \\ National Health and Family Planning Commission, Xiangya Hospital, Central South University, Changsha, Hunan, P.R. China. Email: maoyuli@126.com \\ (c) Ivyspring International Publisher. This is an open access article distributed under the terms of the Creative Commons Attribution (CC BY-NC) license \\ (https://creativecommons.org/licenses/by-nc/4.0/). See http://ivyspring.com/terms for full terms and conditions.
}

Received: 2018.03.07; Accepted: 2018.10.24; Published: 2019.01.01

\begin{abstract}
Background: The radioresistance of nasopharyngeal carcinoma (NPC) was the main cause of radiotherapy failure and it was still a challenge in the treatment of advanced NPC patients. Previous clinical studies demonstrated that sodium glycididazole(CMNA) can enhance the radiosensitivity of NPC, but the corresponding cellular mechanisms or processes remains largely unclear.

Methods: To clarify the radiosensitizing effects of CMNA on NPC cells and reveal its cellular mechanisms, its effect on cell survival of NPC cells was assessed by MTT and clonogenic assay, with or without radiation. The potential cellular mechanisms such as cell cycle distribution, apoptosis and DNA damage were assessed. A retrospective analysis of the outcome of patients with III-IV stage NPC who undergo same radiochemotherapy with or without concurrent CMNA treatment was performed to elucidate the role of CMNA in the improvement of the curative effects.

Results: The treatment with CMNA at the concentration lower or close to the clinical dosage had little effect on cell survival, cell cycle distribution and a weak effect on DNA damage and cell apoptosis of NPC cells. The combination of CMNA and radiation significantly increased the DNA damage and enhanced the apoptosis of NPC cells, but did not significantly alter the cell cycle distribution as compared with the irradiation (IR) alone. A total of 99 patients who underwent radiochemotherapy were categorized into those with (treatment group, $n=52$ ) and without (control group, $n=47$ ) the treatment with CMNA. The complete response rates of patients in treatment group were significantly higher than in control group.

Conclusions: Our results suggested that CMNA enhance the sensitivity of the NPC cells to radiation via enhancing DNA damage and promoting cell apoptosis. It provides clues for further investigation of the molecular mechanism of the radiosensitization of CMNA on NPC cells.
\end{abstract}

Key words: nasopharyngeal carcinoma, sodium glycididazole, radiotherapy, sensitization

\section{Introduction}

Nasopharyngeal carcinoma is a most common malignant cancer in Southeast Asia, which accounts for more than $70 \%$ of the cases worldwide in 2012. The majority of nasopharyngeal carcinoma patients are initially diagnosed with locally advanced cancer [1, 2]. Radiotherapy is a primary and essential treatment of non-disseminated nasopharyngeal carcinoma. However, due to radioresistance, certain NPC 
patients exhibit local recurrences and distant metastases within 2 years after treatment [3, 4]. Moreover, the radiotherapeutic effect for NPC patients in an advanced stage is not efficient as that in primary stage mostly because of radiation resistance [5-8]. How to improve efficacy of treatment for patients with locally advanced nasopharyngeal carcinoma as well as reduce side effects is still one of the research hot spots. Enhancing radiation sensitivity of the tumor cells is one of attractive strategies for achieving the goal, therefore an effective radiotherapy sensitization agent will benefit a large number of patients.

Sodium glycididazole (CMNA) is a new nitroimidazole compound which has a radiationenhancing effect in vivo and in vitro $[9,10]$. CMNA exhibited the effect of enhancing radiation in the treatment of patients with various tumors, such as non-small-cell lung cancer, esophageal carcinoma, differentiated thyroid carcinoma, in clinical trial [11-13]. CMNA combined chemotherapy or radiotherapy in treating patients with locally advanced nasopharyngeal carcinoma could improve curative effects without increasing adverse reactions, and significantly increase survival rates of the patients [14]. But the cellular mechanisms or processes that sodium glycididazole take effect in enhancing radiosensitivity of NPC remain largely unclear.

The most deleterious damage of irradiation is DNA double-strand breaks (DSBs), which induce harmful lesions and causes cell-cycle arrest or cell death [15-18], therefore, most radiation sensitizers target the cellular mechanisms involved in the cell cycle, DNA repair, or apoptosis pathways [19]. In this study, a retrospective analysis was performed to demonstrate that CMNA could improve therapeutic effects of patients with locally advanced NPC. Then, we used in vitro cell models of human NPC to validate the effect of sodium glycididazole on radiation of NPC and uncover the cellular mechanisms through which CMNA take effect as a radiation sensitizer.

\section{Methods}

\section{Cell culture and reagents}

The nasopharyngeal carcinoma cell line 6-10B and HNE2 were obtained from the cell bank of Xiangya School of Medicine(Changsha, China) and were cultured in RPMI 1640 medium (Gibco) with $10 \%$ fetal bovine serum (FBS; Gibco), $100 \mathrm{U} / \mathrm{ml}$ penicillin, and $100 \mathrm{mg} / \mathrm{ml}$ streptomycin (Gibco), under conditions of $5 \% \mathrm{CO}_{2}$ in an incubator at $37^{\circ} \mathrm{C}$. Sodium glycididazole (CMNA) was produced by Shandong Luye Pharma Group Ltd (Yantai, China). Sodium glycididazole was dissolved and diluted in RPMI 1640 medium with $10 \%$ fetal bovine serum when used.

\section{MTT}

Cells were plated at the concentration of $1 \times 10^{3}$ cells/well in 96-well plates and incubated for $12 \mathrm{~h}$. The medium was removed and replaced with or without sodium glycididazole $(0-5 \mathrm{mmol} / \mathrm{L})$, and the cells were incubated for $96 \mathrm{hs}$. Next, $20 \mathrm{ul}$ of MTT $(5 \mathrm{mg} / \mathrm{ml}$; Sigma-Aldrich) was added to each well, and cells were incubated for $4 \mathrm{hs}$ at $37^{\circ} \mathrm{C}$. The medium containing MTT solution was removed, and adding 150ul DMSO, and the plates were shocked for $10 \mathrm{~min}$ at table concentrator. The absorbance was measured at a wavelength of $490 \mathrm{~nm}$. All experiments here were repeated three times.

\section{Colony formation assay}

Cells were seeded onto six-well dishes and incubated overnight. Cells were treated with sodium glycididazole $(1,3,5 \mathrm{mmol} / \mathrm{L})$ or control for $1 \mathrm{~h}$. The cells were then irradiated at a dose of $0,2,4,6,8 \mathrm{~Gy}$ with $6-\mathrm{MV}$ X-rays, $4.0 \mathrm{~Gy} / \mathrm{min}$. The cell culture medium was washed away and replaced with new medium (10\% FBS) after irradiation (IR) for 24 hs. The cells were then cultured in $5 \% \mathrm{CO}_{2}$ incubator at $37^{\circ} \mathrm{C}$ for 7 to 8 days. The colonies were fixed by methanol and stained with crystal violet. The number of colonies containing at least 50 cells was determined.

\section{Cell cycle}

Cells were seeded in 6-well plates and treated with sodium glycididazole ( $3 \mathrm{mmol} / \mathrm{L})$ for $1 \mathrm{~h}$ before irradiation (4Gy) and were harvested at $24 \mathrm{~h}$ after irradiation. The cells were fixed in $70 \%$ ice-cold ethanol and stored at $-4^{\circ} \mathrm{C}$ overnight. Then, the cells were pelleted, washed, and stained with PI/ ribonuclease staining buffer $(\mathrm{BD}, 550825)$ for 15 minutes at room temperature. All experiments were performed at least three times.

\section{Cell apoptosis}

6-10B and HNE2 cells were irradiated at a single dose of 4 Gy after treatment with sodium glycididazole $(3 \mathrm{mmol} / \mathrm{L})$ or cell culture medium for 1h. Cell proteins were extracted after radiation for 48h. Protein content was quantified by the BCA Protein Assay Reagent Kit. The primary antibodies were rabbit anti-c-PARP (1:1000, 5625T, CST) and rabbit anti-caspase 3 (1:800, 19677-1-AP, Proteintech).

\section{Y-H2AX assay}

Cells were plated in chamber slides, incubated overnight, and pretreated with sodium glycididazole ( $3 \mathrm{mmol} / \mathrm{L}) 1 \mathrm{~h}$ before irradiation (4Gy). At $5 \mathrm{~h}$ postirradiation, the cells were fixed with $2 \%$ paraformaldehyde for $15 \mathrm{~min}$ at room temperature. The fixed cells were permeabilized with $1 \%$ Triton-X-100 and 
subsequently blocked with goat serum blocking solution at room temperature for 30 mins. The cells were then incubated overnight at $4^{\circ} \mathrm{C}$ with primary monoclonal antibodies against $\mathrm{Y}$-H2AX (1:300, ab22551, Abcam). After primary antibody incubation, the cells were washed with PBST and incubated with secondary antibody conjugated to FITC (1:200) for $1 \mathrm{~h}$ at room temperature. Nuclei were counterstained with mounting medium DAPI $(1 \mu \mathrm{g} / \mathrm{ml}) .6-10 \mathrm{~B}$ and HNE2 cells were irradiated at a single dose of 4 Gy after treatment with sodium glycididazole $(3 \mathrm{mmol} / \mathrm{L})$ or control for $1 \mathrm{~h}$. Cell proteins were extracted after radiation for 5 hs. Protein content was quantified by the BCA Protein Assay Reagent Kit. The primary antibody was mouse anti- $\gamma-\mathrm{H} 2 \mathrm{AX}$ (1:1000, ab22551, Abcam). For quantitative analysis, $\geq 100$ cells were chosen at random and nuclei counted manually to determine the percentage positive for $\mathrm{\gamma}-\mathrm{H} 2 \mathrm{AX}$ (having $\geq 5$ discrete foci/nucleus). Results were averaged from 3 biological replicates.

\section{Retrospective Analysis}

In order to evaluate the impact of CMNA on the curative effects of radiotherapy, we retrospectively enrolled the patients with locally advanced NPC who underwent radiochemotherapy at Xiangya hospital of Central South University between February 2017 to May 2018. The inclusion criteria of the study were as follows: (1) patients with NPC aged less than 70 years. (2) pathologically diagnosed with undifferentiated carcinoma, differentiated squamous cell carcinoma. (3) patients with locally advanced nasopharyngeal
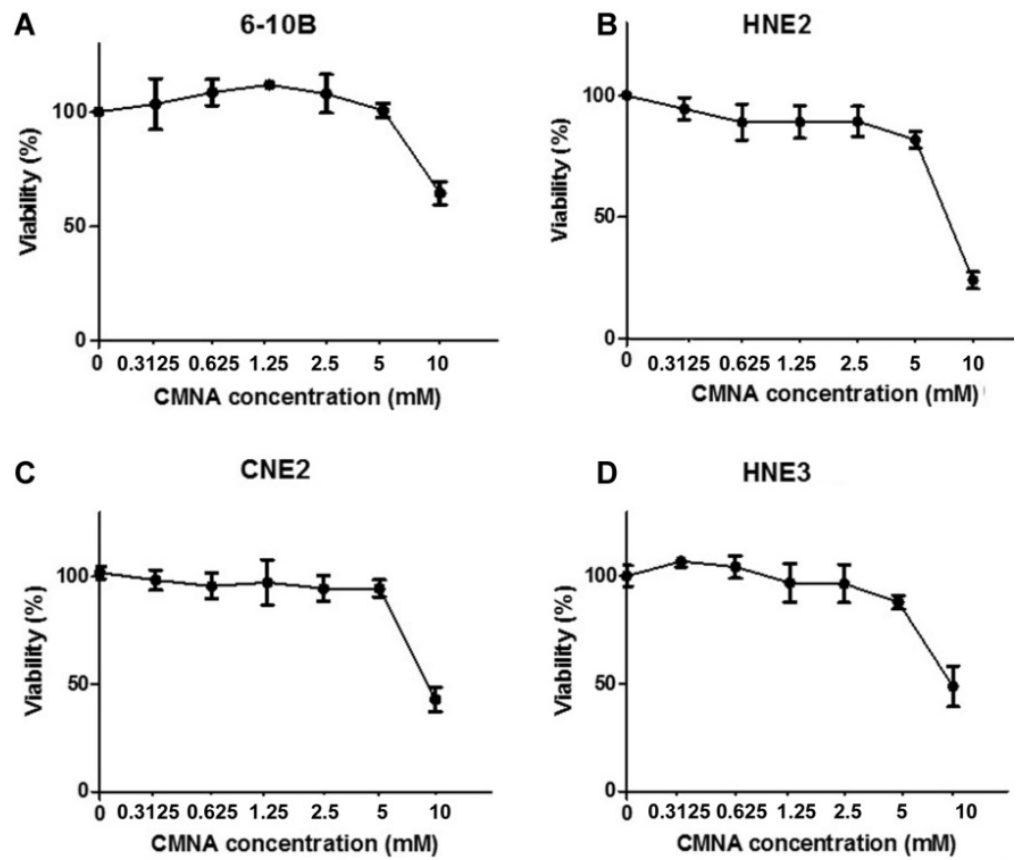

Figure 1. Effect of CMNA on the viability of 6-10B, HNE2, CNE2 and HNE3 cells. The viability of the cells at $96 \mathrm{~h}$ post treatment with the indicated concentrations of CMNA were evaluated by MTT assay $(n=3)$. carcinoma who were in clinical stage III or IV. (4) patients received the same radiochemotherapy regimen. In the present study, all patients received 70.4 Gy of radiation dose and were treated with cis-platinum from $\mathrm{d} 1$ to $\mathrm{d} 3$. Chemotherapy was started from the first week of radiotherapy and repeated every three weeks. Exclusion criteria: diagnosed with other malignant or metastatic NPC. A total of 99 patients who met abovementioned criteria were categorized into the control or the treatment group. For the treatment group, the patients were given CMNA $800 \mathrm{mg} / \mathrm{m} 2$ before radiotherapy. Response was classified according to according to the Response Evaluation Criteria in Solid Tumors (RECIST) [20]. The study was approved by the Institutional Review Board of Xiangya hospital of Central South University.

\section{Statistical analysis}

The measurement data are presented as the mean \pm standard deviation and the significance of difference between mean values was determined by Student's t-test. The counting data were compared with Wilcoxon rank sum test. A p value $<0.05$ was considered statistically significant.

\section{Results}

\section{Effect of CMNA alone or combined with radiation on cell growth}

To evaluate the impact of CMNA on growth of NPC cells, MTT assay was performed to determine the toxicity of CMNA on 6-10B, HNE2, CNE2 and HNE3 cells. As shown in Figure 1, CMNA showed low-toxicity effect on 6-10B, HNE2, CNE2 and HNE3 cells at the concentration of less than $5 \mathrm{mM}$. To determine the effect of CMNA on the radiosensitivity of NPC cells, we pre-treated the four NPC cell lines with vehicle (control) or various concentration of CMNA for one hour, and then exposed cells to $4 \mathrm{~Gy}$ dose of irradiation. The cell viability was evaluated by MTT assay. As shown in Figure 2, the viability of the cells decreased as the concentration of CMNA increased, which demonstrated that CMNA could increase the sensitivity of cells to radiation. It was found that the cell viability of CNE2 and HNE3 was reduced by nearly half, while the cell viability of $6-10 \mathrm{~b}$ and HNE2 was reduced by only $10-20 \%$ after exposed to radiation when no CNMA was used. It demonstrated that CNE2 and HNE3 are more sensitive to radiation than 6-10B and 
HNE2. Therefore, the cell lines 6-10B and HNE2 were selected for follow-up experiments as they were more suitable for discovery and proof-of-concept studies because of being more resistant to radiation.

To further evaluate the long-term toxicity of CMNA, the effect of various concentrations of CMNA
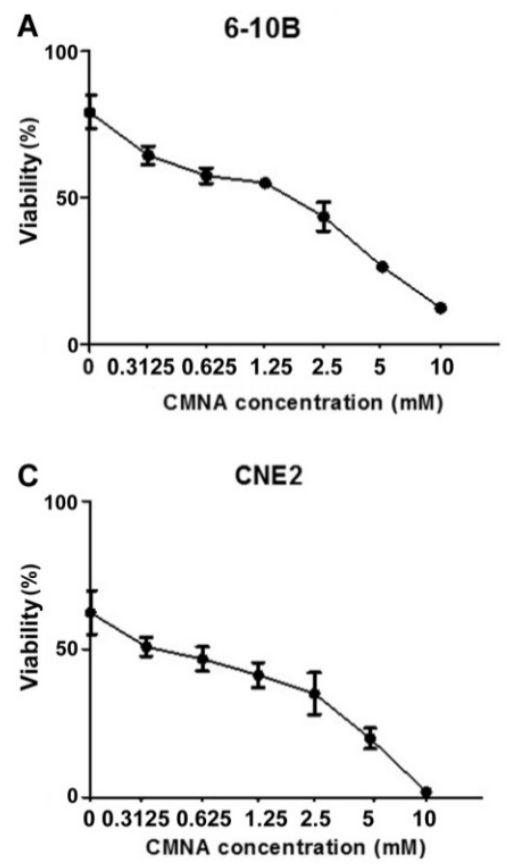

on clonogenic ability of $6-10 \mathrm{~B}$ and HNE2 cells was detected. As seen in Figure $3 a$ and $3 b$ the colony number was comparable in various concentrations, which demonstrated that CNMA have no apparent inhibitory effect on colony-forming ability of 6-10B and HNE2.

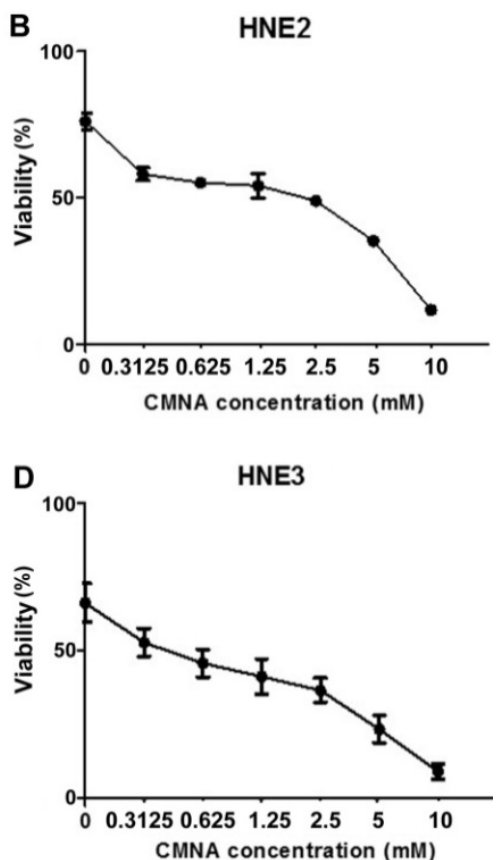

Figure 2. CMNA enhances the radiosensitivity of the NPC cells. After pre-treated with vehicle or various concentrations of CMNA ( $0.3125,0.625,1.25,2.5,5,10$ $\mathrm{mmol} / \mathrm{L}$ ) and then irradiated at the dose of $4 \mathrm{~Gy}$, the viability was tested by MTT assay.
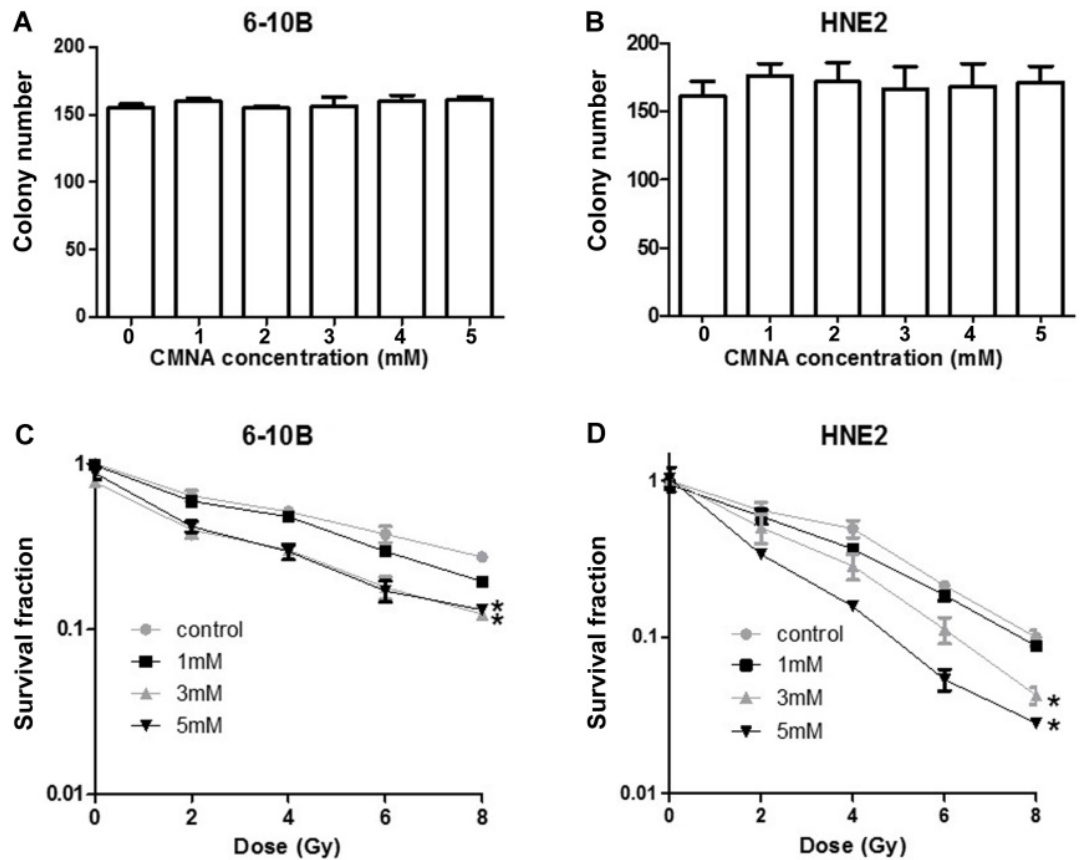

Figure 3. Effect of CMNA alone or combined radiation on cell clonogenic ability. The clonogenic ability of 6-10B(a) and HNE2(b) cells at 24h post treatment with vehicle or various concentrations $(1,2,3,4,5 \mathrm{mmol} / \mathrm{L})$ of CMNA $(n=3)$. After pre-treated with vehicle or various concentrations of $C M N A(1,3,5 \mathrm{mmol} / \mathrm{L})$, and then irradiated with a series of doses, the survival fraction of $6-10 \mathrm{~B}$ and HNE2 cells at 7 days post initial treatment were determined by clonogenic assay. ( $\mathrm{n}=3$, $* P<0.05$ for $\mathrm{CMNA}$ at concentration ( 3 or $5 \mathrm{mM}$ ) as compared to control) 
A
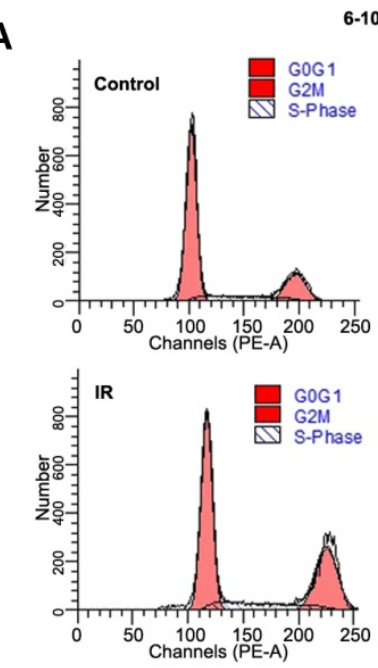

$6-10 B$
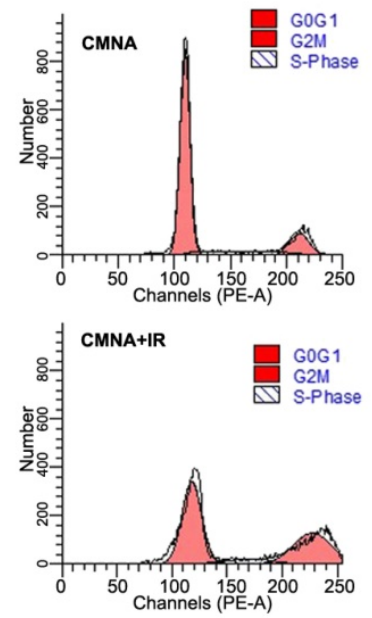

C

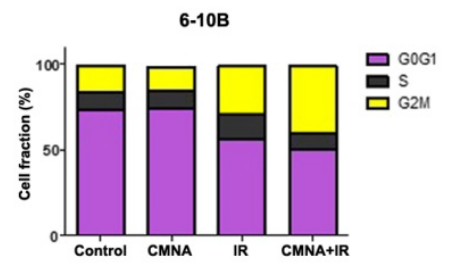

B

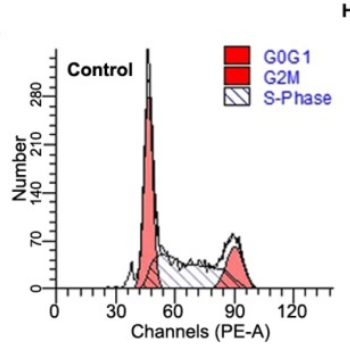

HNE2
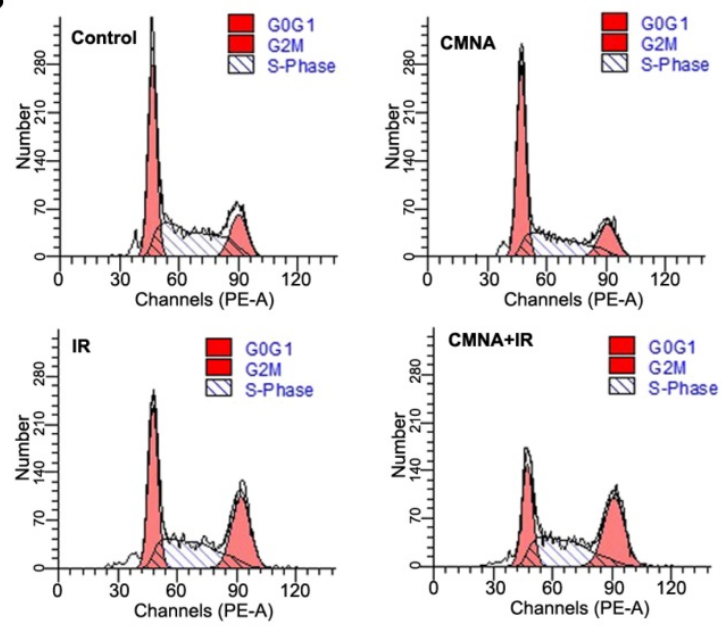

D

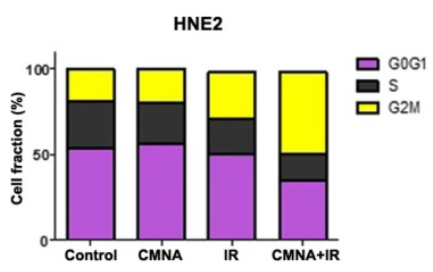

Figure 4. Cell cycle distribution after irradiation is not altered by CMNA. (a, b) Propidium iodide staining and flow-cytometry analysis 24 hs after the treatment in 6-10B and HNE2 cells. (c, d) The percentage of cells in G0/G1, S, and G2/M phase of the cell cycle before and after radiation (4 Gy) with and without pretreatment with CMNA for $1 \mathrm{~h}$.

\section{CMNA enhances the radiosensitivity of 6-10B and HNE2 cell}

To further determine the effect of CMNA on the radiosensitivity of NPC cells, we pre-treated 6-10B and HNE2 cells with various concentration of CMNA for $1 \mathrm{~h}$, and then exposed cells to different doses of irradiation. Clonogenic survival assay was performed to assess the radiosensitizing effect of CMNA. As shown in Figure $3 \mathrm{c}$ and $3 \mathrm{~d}$, the addition of CMNA further reduced the survival fraction at various dose of radiation and increase the inhibitory effects of radiation. In addition, along with the increasing of drug concentrations the inhibitory effects were more significant, which suggested that CMNA can enhance the radiosensitivity of NPC cells and the effect was dose dependent.

According to the above result, the optimized CMNA concentration of $3 \mathrm{mM}$ and the propriate dose of irradiation of $4 \mathrm{~Gy}$ were determined to investigate the cellular mechanisms behind the effect of CMNA on radiosensitivity of NPC cells in the following experiments.

\section{CMNA regulates the cell cycle in 6-10B and HNE2 cells}

To clarify whether CMNA-mediated radiosensitization was due to its impact on the cell cycle redistribution, the cell cycle of 6-10B and HNE2 after irradiation with or without the CMNA pre-treatment were analyzed by flow cytometry. As shown in Figure 3, after treated with CMNA alone for 24 hs, the cell cycle distribution in both examined cell lines did not markedly change as compared to the controls. Cells were treated with CMNA for $1 \mathrm{~h}$ and then expose to radiation, the cell cycle analysis after 24 hs demonstrated the percentage of cells at G2/M phase significantly increased after radiation, which was accompanied by a significantly decreased G0/G1 phase compared to the controls $(\mathrm{p}<0.05)$. In both cell lines, however, the percentage of G2/M-phase cells had no significant alteration between the irradiation with or without CMNA treatment $(\mathrm{p}>0.05)$.

\section{Radiotherapy combined CMNA promotes apoptosis}

We next investigated whether CMNA enhanced radiosensitivity of NPC cells was associated with the increase of apoptosis induced by irradiation. Cells were exposed to $3 \mathrm{mM}$ CMNA for $1 \mathrm{~h}$, and then irradiated with a dose of 4 Gy. Expression of apoptosis markers, active caspase- 3 and cleaved forms of PARP, were assessed in 6-10B and HNE2 cells at 48 hs after treatment. As shown in Figure 4, irradiation increased the expression of the apoptosis marker activated caspase- 3 as well as cleaved PARP, whereas CMNA pre-treatment resulted in greater expression of activated caspase- 3 and cleaved forms of PARP induced by irradiation in both 6-10B and HNE2 cells 
(Figure 4). The result suggested that CMNA could enhance the apoptosis induced by irradiation.

\section{CMNA regulates DNA repair processes in 6-10B and HNE2 cell}

DNA damage caused by radiation play a key role in radiotherapy. Theoretically, what can amplify DNA damage induced by radiation could increase the radiosensitivity. Whether could CMNA enlarge the extent of DNA damage induced by radiation? Previous study reported that the nuclear foci of $\mathrm{\gamma}-\mathrm{H} 2 \mathrm{AX}$ is one of the markers for evaluating the level of DNA damage [21]. To address the question, the formation of $\mathrm{\gamma}-\mathrm{H} 2 \mathrm{AX}$ foci in cell nuclei was evaluated. Cells were treated with or without CMNA for $1 \mathrm{~h}$ prior to irradiation (4 Gy) and fed with CMNA-free medium, and the average number of foci per cell was measured at 5h. As shown in Figure 5, the results demonstrated that exposure of NPC cells to CMNA result in no marked alteration in the number of $\mathrm{\gamma}-\mathrm{H} 2 \mathrm{AX}$ foci as compared to the control, while exposure to either radiation or the combination of radiation and CMNA lead to a significant increase of $\mathrm{Y}-\mathrm{H} 2 \mathrm{AX}$ foci as compared to the control. More importantly, the combination of CMNA and radiation resulted in a greater number of g-H2AX foci than either CMNA or irradiation alone.

We further assessed the level of phosphorylated histone H2AX ( $\gamma-\mathrm{H} 2 \mathrm{AX})$, which forms foci at DNA double strand breaks (DSB) and recruits DSB repair proteins. As shown in Figure $5 c$, radiation induced $\mathrm{Y}-\mathrm{H} 2 \mathrm{AX}$ formation in both NPC cell lines, and the addition of CMNA further increase the level of $\mathrm{\gamma}-\mathrm{H} 2 \mathrm{AX}$. These results demonstrated that CMNA could enlarge the extent of DNA damage induced by radiation.

\section{Patient characteristics}

According to pathological diagnosis, there were 99 patients (66 male and 33 female) with locally advanced (T1-4 N0-3, III-IV) NPC. 47 patients were diagnosed with clinical stage III, 52 patients with stage IV. All patients were categorized into treatment group (radiochemotherapy plus CMNA) and control group (radiochemotherapy). Clinical characteristics of two groups were shown in Table 1, there was no statistically significant difference between two groups $(p>0.05)$.

\section{Response rate}

Evaluated by CT on NPC, (CR+PR) in two groups were $96.2 \%$ and $82.9 \%$ when the radiation dose reached $70.4 \mathrm{~Gy}$. Complete response rate (CR) of treatment group was higher than control group, and the difference was statistically significant $(\mathrm{p}<0.05$, Table 2).

Table 1. Characteristics of patients

\begin{tabular}{llll}
\hline & $\begin{array}{l}\text { Treatment group } \\
(\mathbf{n}=52)\end{array}$ & $\begin{array}{l}\text { Control group } \\
(\mathbf{n = 4 7})\end{array}$ & p value \\
\hline Gender & & & 0.811 \\
M & 34 & 32 & \\
F & 18 & 15 & 0.781 \\
Age & & & \\
$<50$ & $32(61.5 \%)$ & $27(57.4 \%)$ & \\
$>50$ & $20(38.5 \%)$ & $20(42.6 \%)$ & 0.084 \\
Pathological type & & & \\
Undifferentiated carcinoma & $37(71.1 \%)$ & $45(95.7 \%)$ & \\
Keratinizing carcinoma & $10(19.2 \%)$ & $0(0 \%)$ & \\
Non-keratinizing carcinoma & $5(9.7 \%)$ & $2(5.3 \%)$ & \\
T stage & & & \\
T1 & $2(3.8 \%)$ & $3(6.4 \%)$ & \\
T2 & $6(11.5 \%)$ & $7(14.9 \%)$ & \\
T3 & $25(48.1 \%)$ & $20(42.6 \%)$ & \\
T4 & $19(36.5 \%)$ & $17(36.2 \%)$ & \\
N stage & & & \\
N0 & $2(3.8 \%)$ & $5(10.6 \%)$ & \\
N1 & $15(28.8 \%)$ & $15(31.9 \%)$ & \\
N2 & $26(50.0 \%)$ & $15(31.9 \%)$ & \\
N3 & $9(17.4 \%)$ & $12(25.5 \%)$ & \\
Clinical stage & & & \\
III & $27(51.9 \%)$ & $20(42.6 \%)$ & \\
IV & $25(48.1 \%)$ & $27(57.4 \%)$ & \\
\hline
\end{tabular}

Table 2. A comparison on response rate between treatment and control group

\begin{tabular}{llll}
\hline Prognosis & Treatment group(n=52) & Control group(n=47) & $p$ value \\
\hline CR rate & $17(32.7 \%)$ & $2(4.2 \%)$ & 0.020 \\
PR rate & $33(63.5 \%)$ & $37(78.7 \%)$ & \\
SD rate & $2(3.8 \%)$ & $8(17.1 \%)$ & \\
${ }^{*} \mathrm{CR}=$ complete response, $\mathrm{PR}=$ partial response, $\mathrm{SD}=$ stable disease &
\end{tabular}

\section{Discussion}

Although NPC is highly radiosensitive and radiotherapy is the primary and only curative
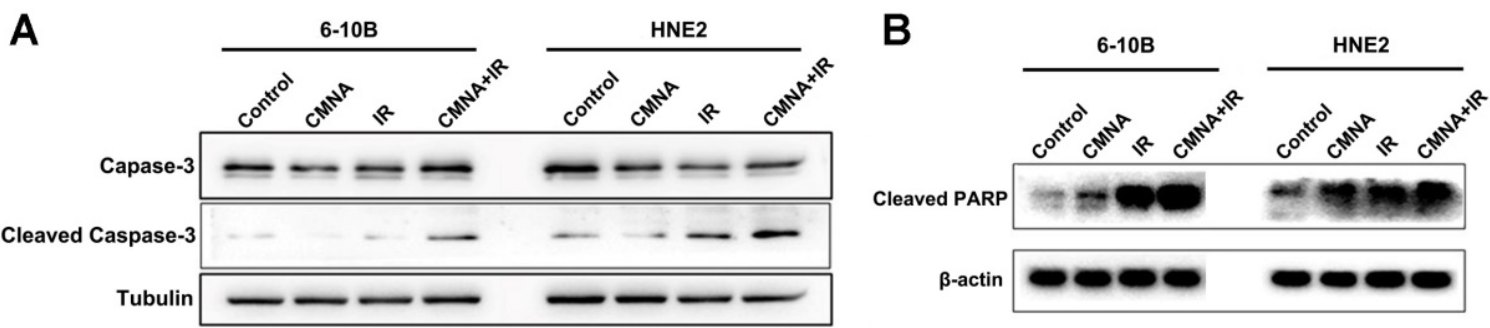

Figure 5. Cell apoptosis after irradiation with or without pretreatment with CMNA. Western blots show that sodium glycididazole pretreatment increases the expression of the apoptosis markers (cleaved forms of PARP and caspase3) induced by irradiation. 
treatment for nasopharyngeal carcinoma, radioresistance inevitably occurred in many cases [22, 23]. Researchers are trying to find new substances that will make tumors more sensitive to radiation without affecting normal tissues [24]. Previous study showed that sodium glycididazole has enhancing effect on radiosensitivity of nasopharyngeal carcinoma cells [14]. A clinical trial also demonstrated that CMNA enhanced the sensitivity to radiation therapy and improved survival rates with minimal side effects in nasopharyngeal carcinoma [18]. CMNA enhancing effect on radiosensitivity has also been observed in other tumors including non-small-cell lung cancer, laryngeal cancer and esophageal carcinoma [11, 12, 25]. Retrospective analysis also demonstrated that CMNA could increase the CR ratio and improved the curative effect of radiotherapy on NPC. It is unambiguous that CMNA has radiationenhancing effect. However, the underlying mechanisms that CMNA enhance the radiosensitivity of tumor cells remained largely unknown, although it has been reported that CMNA enhances the radiosensitivity of laryngeal cancer cells through downregulation of ATM signaling pathway, which may regulate the DNA repair of radiation response [25].

The present study demonstrated that the treatment of NPC cells with CMNA alone had no significant effect on tumor cell proliferation, while it can enhance the radiosensitivity of the NPC cell lines. The 6-10B and HNE2 cells treated with the combination of CMNA and irradiation were shown significant growth inhibition. In order to clarify the underlying mechanism that CMNA enhance the radiosensitivity of NPC cells, we firstly determined whether CMNA enhances the radiosensitivity of NPC through redistributing cell cycle growth phases. We observed that CMNA alone had no significant effect on the cell cycle in NPC cells. Intriguingly, CMNA combined with ionizing radiation did not induced a significantly higher G2/M arrest in 6-10B and HNE2 cells compared with radiation alone. The result indicated that CMNA alone did not redistribute the cell cycle of NPC cells. Moreover, the cell cycle distribution between irradiated NPC cells with and without CMNA treatment had no significant difference. This phenomenon was also found in the study about another potential radiation sensitizer [26]. Accordingly, we speculated that it was not through redistributing the cell cycle that CMNA enhances the radiosensitivity of NPC.

Radiation therapy achieves its therapeutic effects by inducing apoptosis or non-apoptotic cell death [27]. Therefore, we want to know whether CMNA enhances the radiosensitivity of NPC through promoting apoptosis of NPC cells. To answer this question, western blotting assay were performed on irradiated NPC cells that were exposed to CMNA to evaluate the expression of apoptotic markers. We observed that CMNA alone was not able to induce apoptosis of cancer cells. However, the combination of CMNA and radiation led to more apoptosis of NPC cells than radiation alone. Consistent with the present result, earlier study also demonstrated that CMNA increased apoptosis induced by irradiation in laryngeal cancer cells [25].

Agents that increase the extent of DNA damage or that inhibit DNA double strand break repair often sensitize tumor cells to irradiation [28]. To further investigate the effects of CMNA treatment on DNA damage and repair, an immunofluorescent staining assay were performed to detect gamma-H2AX levels and measure DNA double strand breaks at 5 hs. As indicated in Fig. 6, it suggested that CMNA alone caused no change in gamma- $\mathrm{H} 2 \mathrm{AX}$ levels, but
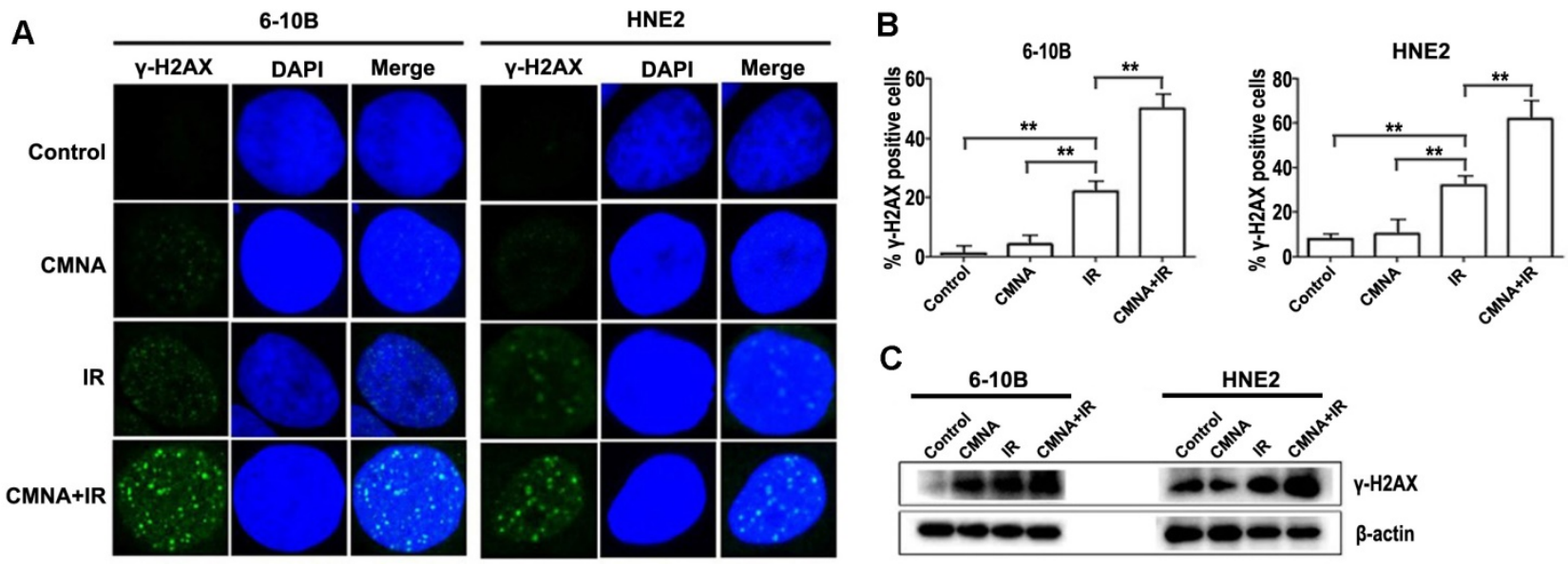

Figure 6. CMNA regulates DNA repair processes in 6-10B and HNE2 cell. (a). Irradiation with $4 \mathrm{GY}$ of ionizing radiation and pretreatment with $\mathrm{CMNA}$ ( $3 \mathrm{mmol} / \mathrm{L}$ ) induces $\mathrm{Y}-\mathrm{H} 2 \mathrm{AX}$ foci formation in both NPC cells. $\mathrm{Y}-\mathrm{H} 2 \mathrm{AX}$ foci per cell increases $5 \mathrm{~h}$ after radiation and is further enhanced by pretreatment with $\mathrm{CMNA}$ in $6-10 \mathrm{~B}$ and $\mathrm{HNE} 2$. (b). Mean percent of cells with $\geq 5 \mathrm{Y}-\mathrm{H} 2 \mathrm{AX}$ foci, $\pm \mathrm{SEM}$; data were combined from three experiments. **p $<0.01$. (c). Western blots of $\mathrm{Y}-\mathrm{H} 2 \mathrm{AX}$ show that irradiation increases the DNA damage (the level of $\mathrm{Y}-\mathrm{H} 2 \mathrm{AX}$ ), which is further enhanced by irradiation combined sodium glycididazole. 
radiation or the combination of CMNA and radiation did. It was worth noting that the cells treated with the combination CMNA and irradiation had higher $\mathrm{Y}-\mathrm{H} 2 \mathrm{AX}$ levels than those treated with radiation alone. Indeed, previous study demonstrated that the CMNA can regulate the ATM pathway, which is key pathway that mediates the radiation-induced DNA damage and repair [25].

The data presented here showed that the pretreatment of irradiated NPC cells with CMNA resulted in a dose-dependent induction of clonogenic cell death. Our results demonstrate that CMNA can enhance the radiosensitivity of NPC via promote apoptosis and impairing DNA damage and repair. These findings provided clues for further revealing the molecular mechanisms behind radiosensitization of CMNA and optimization of irradiation treatment strategy of NPC.

\section{Acknowledgements}

This work was supported by Natural Science Foundation of China [81372904], and Natural Science Foundation of Hunan Province of China [2015JJ2163].

\section{Competing Interests}

The authors have declared that no competing interest exists.

\section{References}

[1] Ouyang P Y, Su Z, Ma X H, et al. Comparison of TNM staging systems for nasopharyngeal carcinoma, and proposal of a new staging system. Br J Cancer. 2013;109(12): 2987-97.

[2] Zhao L, Tang M, Hu Z, et al. miR-504 mediated down-regulation of nuclear respiratory factor 1 leads to radio-resistance in nasopharyngeal carcinoma. Oncotarget. 2015;6(18): 15995-6018.

[3] Al-Sarraf M, Reddy M S. Nasopharyngeal carcinoma. Curr Treat Options Oncol. 2002;3(1): 21-32.

[4] Lu J, Tang M, Li H, et al. EBV-LMP1 suppresses the DNA damage response through DNA-PK/AMPK signaling to promote radioresistance in nasopharyngeal carcinoma. Cancer Lett. 2016;380(1): 191-200.

[5] Chan A T, Gregoire V, Lefebvre J L, et al. Nasopharyngeal cancer: EHNS-ESMO-ESTRO Clinical Practice Guidelines for diagnosis, treatment and follow-up. Ann Oncol. 2012;23(Suppl 7): vii83-5.

[6] Chan A T, Felip E. Nasopharyngeal cancer: ESMO clinical recommendations for diagnosis, treatment and follow-up. Ann Oncol. 2009;20(Suppl 4): 123-5.

[7] Thompson L. World Health Organization classification of tumours: pathology and genetics of head and neck tumours. Ear Nose Throat J. 2006;85(2): 74

[8] Zhao Y, Shen L, Huang X, et al. High expression of Ki-67 acts a poor prognosis indicator in locally advanced nasopharyngeal carcinoma. Biochem Biophys Res Commun. 2017;494(1-2): 390-396.

[9] Zeng Y C, Wu R, Xu Z G, et al. Safety and radiation-enhancing effect of sodium glycididazole in locoregionally advanced laryngeal cancers previously treated with platinum-containing chemotherapy regimens: A preliminary report. Cancer Radiother. 2010;14(1): 59-64.

[10] Zheng X, Gao J, Zhang H, et al. Radiosensitizing efficiency of sodium glycididazole on v(79) cells in vitro. J Radiat Res Radiat Proc. 1995;13(4): 213-218.

[11] Yang J, Liu M Z, Cai L, et al. [Phase II clinical trial of sodium glyci-didazole (CM-Na) combined with concurrent radiochemotherapy for advanced esophageal carcinoma]. Ai Zheng. 2008;27(6): 622-6.

[12] Zhang Q, Wang D Q, Wu Y F. Sodium glycididazole enhances the efficacy of combined iodine-125 seed implantation and chemotherapy in patients with non small-cell lung cancer. Oncol Lett. 2015:9(5): 2335-2340.

[13] Wen Q, Ma Q, Bai L, et al. Glycididazole sodium combined with radioiodine therapy for patients with differentiated thyroid carcinoma (DTC). Int J Clin Exp Med. 2015;8(8): 14095-9.

[14] Li M Y, Liu J Q, Chen D P, et al. Glycididazole sodium combined with radiochemotherapy for locally advanced nasopharyngeal carcinoma. Asian Pac J Cancer Prev. 2014;15(6): 2641-6.
[15] Huang S M, Harari P M. Modulation of radiation response after epidermal growth factor receptor blockade in squamous cell carcinomas: inhibition of damage repair, cell cycle kinetics, and tumor angiogenesis. Clin Cancer Res. 2000;6(6): 2166-74

[16] Rastogi R P, Richa, Kumar A, et al. Molecular mechanisms of ultraviolet radiation-induced DNA damage and repair. J Nucleic Acids. 2010;2010: 592980

[17] Jackson S P, Bartek J. The DNA-damage response in human biology and disease. Nature. 2009;461(7267): 1071-8.

[18] Jun S, Jung Y S, Suh H N, et al. LIG4 mediates Wnt signalling-induced radioresistance. Nat Commun. 2016;7: 10994.

[19] Citrin D E, Mitchell J B. Altering the response to radiation: sensitizers and protectors. Semin Oncol. 2014;41(6): 848-59.

[20] Eisenhauer E A, Therasse P, Bogaerts J, et al. New response evaluation criteria in solid tumours: revised RECIST guideline (version 1.1). Eur J Cancer. 2009;45(2): 228-47.

[21] Ferguson D O, Sekiguchi J M, Frank K M, et al. The interplay between nonhomologous end-joining and cell cycle checkpoint factors in development, genomic stability, and tumorigenesis. Cold Spring Harb Symp Quant Biol. 2000;65: 395-403.

[22] Chua M, Wee J, Hui E P, et al. Nasopharyngeal carcinoma. Lancet. 2016;387(10022): 1012-1024

[23] Zhang L, Yang L, Li J J, et al. Potential use of nucleic acid-based agents in the sensitization of nasopharyngeal carcinoma to radiotherapy. Cancer Lett. 2012;323(1): 1-10.

[24] Begg A C, Stewart F A, Vens C. Strategies to improve radiotherapy with targeted drugs. Nat Rev Cancer. 2011;11(4): 239-53.

[25] Zeng Y C, Xing R, Zeng J, et al. Sodium glycididazole enhances the radiosensitivity of laryngeal cancer cells through downregulation of ATM signaling pathway. Tumour Biol. 2016;37(5): 5869-78.

[26] Gordon I K, Graves C, Kil W J, et al. Radiosensitization by the novel DNA intercalating agent vosaroxin. Radiat Oncol. 2012;7: 26.

[27] Balcer-Kubiczek E K. Apoptosis in radiation therapy: a double-edged sword. Exp Oncol. 2012;34(3): 277-85.

[28] Thoms J, Bristow R G. DNA repair targeting and radiotherapy: a focus on the therapeutic ratio. Semin Radiat Oncol. 2010;20(4): 217-22. 